\title{
Evaluation of the Usefulness of FDG-PET/CT for Nodal Staging of Breast Cancer
}

\author{
PAOLO ORSARIA ${ }^{1}$, AGOSTINO CHIARAVALLOTI $^{2}$, EMANUELE CAREDDA $^{2}$, PAOLA VALERIA MARCHESE ${ }^{1}$, \\ BRISIDA TITKA $^{2}$, LUCIA ANEMONA ${ }^{2}$, ILARIA PORTARENA ${ }^{3}$, ORAZIO SCHILLACI $^{2}$, \\ GIUSEPPE PETRELLA ${ }^{1}$, LEONARDO PALOMBI ${ }^{2}$ and ORESTE CLAUDIO BUONOMO ${ }^{1}$ \\ ${ }^{1}$ Department of Surgery, Tor Vergata University Hospital, Rome, Italy; \\ ${ }^{2}$ Department of Biomedicine and Prevention, Tor Vergata University Hospital, Rome, Italy; \\ ${ }^{3}$ Medical Oncology Unit, Department of Internal Medicine, Tor Vergata University Hospital, Rome, Italy
}

\begin{abstract}
Background/Aim: Positron emission tomography/ computed tomography (PET/CT) with ${ }^{18} \mathrm{~F}$-fluorodeoxyglucose (18F-FDG) has recently been used to investigate lymph node $(L N)$ metastases and several predictive features in patients with breast cancer $(B C)$. The aim of this study was to assess the value of this non-invasive imaging procedure for axillary staging. Patients and Methods: Fifty patients with early primary unilateral, locally advanced, or recurrent invasive operable $B C$ were enrolled. All patients underwent preoperative $18 F-F D G \quad P E T / C T$, and the results were compared with the histopathology of dissected axillary LNs and their biological and immunohistochemical characteristics. The diagnostic performance of $18 F-F D G$ PET/CT in detecting $L N$ metastases from primary or recurrent $B C$ was analyzed. The mean values of the initial PET/CT parameters, including the primary tumour (SUVT) and ipsilateral axillary LNs (SUV $L N)$, were compared with the clinicopathological features of patients to determine their usefulness for predicting clinical interactions. Results: The sensitivity, specificity, overall accuracy, positive predictive value, and negative predictive value of $18 F-F D G$ PET/CT for axillary LN staging were $87 \%$, $90 \%, 88 \%, 93 \%$, and $82 \%$, respectively. Bivariate analyses showed strong interactions of nuclear grade $(p=0.05)$, progesterone receptor expression $(p=0.001)$, Ki-67 index (0.027), and local relapse with the SUV T. A high SUV LN value was significantly correlated with a higher nuclear grade score $(p=0.05)$, oestrogen receptor negativity $(p=0.001)$, progesterone receptor negativity $(p=0.014)$, a high Ki-67 index (>20\%; $p=0.048)$, LN metastasis $(p<0.001)$, a basal
\end{abstract}

Correspondence to: Paolo Orsaria, Department of Surgery, Tor Vergata University Hospital, 81 Oxford Street, 00133 Rome, Italy. Tel: +39 3282492485, e-mail: orsaria@aol.it

Key Words: Breast cancer, metabolic pathways, prognostic microenvironment, nodal staging, FDG-PET/CT. tumour $(p=0.04)$, and locoregional recurrence $(p<0.001)$. Conclusion: PET/CT is a reproducible, non-invasive imaging modality that is useful for evaluating a primary BC mass and its relationship with metastatic axillary LNs, thereby predicting tumour behaviour and guiding clinical practice.

Traditionally, pathologic determination of tumour size, histological grade, axillary lymph node (LN) involvement, and hormone receptor and human epidermal growth factor receptor-2 (HER2) status have been used as prognostic factors in patients with breast cancer (BC). Determination of the Ki-67 index is also strongly recommended at the time of planning targeted therapies, given that its positivity is associated with a higher probability of relapse and worse overall survival $(1,2)$.

It has since long been recognized that accurate evaluation of locoregional nodal status is essential because of its implications in treatment and prognosis. The 10-year survival rate in patients with axillary LN metastases depends on the number of nodes involved and ranges from $30 \%$ (>10 nodes) to $70 \%$ (1-3 nodes), compared with $90 \%$ in those without these metastases (3). However, management of the axilla in patients with operable $\mathrm{BC}$ is still one of the most controversial areas in clinical oncology. For a long time, the standard procedure used for the assessment of locoregional progression has been axillary LN dissection (ALND), which is associated with significant morbidity, including arm and shoulder pain, lymphedema, nerve injury, hematoma, and limitation of shoulder movement (4). Moreover, ALND does not provide a survival advantage when the LNs are tumournegative (5). In this context, sentinel LN biopsy (SLNB) is a significant advancement in clinical practice. Nevertheless, false-negative (FN) axillary results can occur in up to $15 \%$ of patients, and there is also concern that the disease may be upstaged when SLNB is coupled with very thorough pathological examination (immunohistochemical analysis and multistep sectioning of sentinel nodes) that may detect 
micrometastases, the clinical relevance of which has still to be demonstrated (6).

Based on these considerations, in order to make progress in the treatment of operable $\mathrm{BC}$, new strategies should be developed that permit a less invasive method of axillary sampling and do not impair patient's quality of life. Positron emission tomography/computed tomography (PET/CT) with ${ }^{18} \mathrm{~F}$-fluorodeoxyglucose $(18 \mathrm{~F}-\mathrm{FDG})$ is a recently developed imaging modality that has been used for the investigation of nodal metastases and several predictive features in patients with cancer. FDG-PET/CT imaging reflects the higher glycolytic rate of cancer cells compared to normal cells, allowing discrimination based on metabolic rate. This ability offers potential advantages for detection of subclinical metastases when compared with radiological criteria, which are based on anatomical findings (7).

Unlike conventional morphologic diagnostic imaging, FDG-PET is a functional diagnostic imaging technique that quantifies and evaluates the activity of cancer cells by measuring the maximum standardized uptake value $\left(\mathrm{SUV}_{\max }\right)$ before and after chemotherapy, and is a new tool for assessment of the aggressiveness of the disease $(8,9)$. However, a definitive conclusion remains to be reached concerning the prognostic relevance of the level of $18 \mathrm{~F}$ FDG uptake in BC, and the cut-off value for the SUV reduction rate with regard to the diagnosis of responders and non-responders varies in different reports $(10,11)$. Future studies on the effects of neoadjuvant chemotherapy using FDG-PET scans will need to standardize the histologic evaluation criteria and include the consequences for axillary LNs (12). In this context, a correlation of the level of the SUV in BC with clinicopathological parameters may have prognostic implications in terms of predicting biological characteristics and the baseline risk pretherapeutically. Indeed, the distribution of FDG uptake has been associated with underlying pathophysiological characteristics, including vascularization, perfusion, tumour aggressiveness, necrosis, hypoxia, and gene expression (13, 14). Therefore, we hypothesized that significantly different values for PET image-derived heterogeneity may be observed between the different histological profiles and molecular subgroups of $\mathrm{BC}$, assuming that heterogeneous parameters such as tumour phenotype, nuclear pleomorphism, and steroid receptor and HER2 status, together with the Ki-67 index, have different underlying pathophysiological properties. Parallel to the development of techniques to identify favourable tumour biology and the ability to select patients who are expected to have a more protracted disease course or tumours that are responsive to systemic therapies, more patients will be considered for metastasectomy or cytoreductive surgical techniques $(15$, 16). PET imaging, with further refinements in technical performance, might prove to be a very useful tool for functional and biological localization of malignant lesions, with all the recognized limitations (17).

Current recommendations do not incorporate the routine use of 18F-FGD PET/CT for staging primary BC, and direct scientific evidence to support the ability of this procedure to impact the management procedure is limited (18). First, the true incidence of primary $\mathrm{BC}$ in its various stages that is detectable by 18F-FDG PET/CT needs to be assessed systematically. FDG uptake may then provide quantitative information on both the primary tumour and metastatic LNs additional to that obtained by clinicopathological methods. How such detection aids targeted individualized treatment and alters survival and quality of life should then be assessed. Finally, the cost to the health service provider of performing this procedure needs to be accurately calculated.

In this study, the value of full diagnostic FDG-PET/CT for axillary LN staging in patients with $\mathrm{BC}$ was assessed, evaluating at the same time the possible influence of biological markers on the glycolytic pathways. The aims of the study were to determine the sensitivity, specificity, accuracy, positive predictive value (PPV), and negative predictive value (NPV) of FDG-PET/CT and to assess the possible role of this imaging modality in preselection of candidates for SLNB instead of immediate ALND. However, more detailed knowledge of the initial clinicopathological implications for optimal use and interpretation of this noninvasive imaging technique are needed before a definitive conclusion can be reached concerning the prognostic relevance of the preoperative level of $18 \mathrm{~F}-\mathrm{FDG}$ uptake in BC. Further studies need to be performed in large numbers of patients to verify these results and to further investigate the role of PET/CT in staging of BC, particularly in the detection of axillary nodal involvement and inherently aggressive biological criteria with poorer clinical outcomes, for an optimal disease-tailored approach to management of locoregional and systemic disease.

\section{Materials and Methods}

Study design and conduct. A total of 50 consecutive eligible patients (48 women, two men, aged 34-88 years) with early primary unilateral, locally advanced, or recurrent invasive $\mathrm{BC}$ were prospectively recruited for preoperative staging by $18 \mathrm{~F}-\mathrm{FDG}$ PET/CT between November 2015 and July 2018. All patients had undergone triple assessment including mammography, ultrasonography, and core biopsy, prior to recruitment. The indication for surgery, the surgical strategy, and study eligibility were determined on the basis of the findings of preoperative PET/CT imaging and no evidence of distant metastases. The functional imaging evaluation of the presence or absence of regional nodal spread of malignancy (quantitative and semiquantitative analysis, see below) was compared with the reference standard for assessment of the axillary nodes, i.e., a histological examination of resected axillary LNs obtained by SLNB alone, by SLNB and ALND, or by ALND alone. Forty-four patients $(88 \%)$ with histologically proven primary $\mathrm{BC}$ were required to 

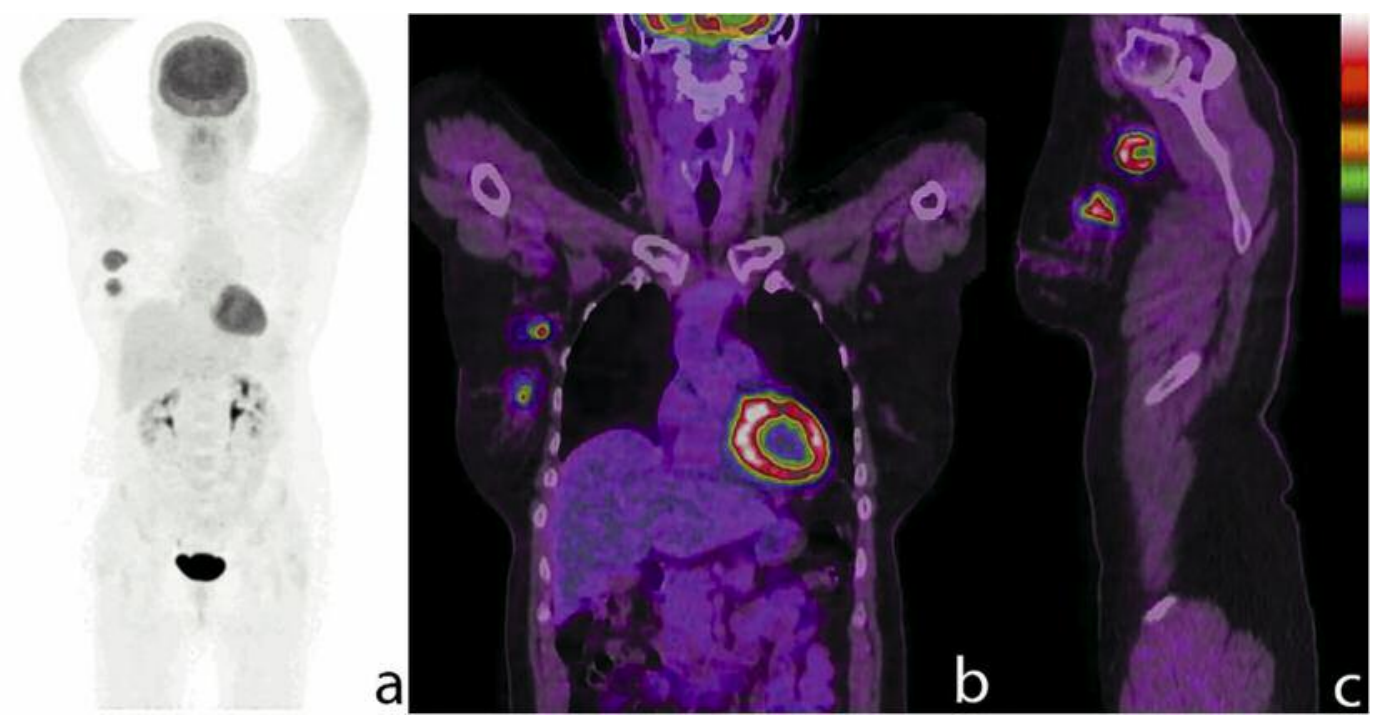

Figure 1. Maximum intensity projection of positron-emission tomography images showing the ${ }^{18}$ F-fluorodeoxyglucose distribution in patient 1. Coronal ( $a-b)$ and sagittal (c) positron-emission tomography / computed tomographic images demonstrating hypermetabolic lesions in the upperouter quadrant of right breast (SUV T=9.1) and in the right axilla (SUV LN=10.3).

proceed to SLNB or ALND after completion of PET/CT and to undergo a level I/II ALND after SLNB, if the SLNB result was positive, or if the PET/CT scan showed increased uptake in the ipsilateral axilla. Nine $(20 \%)$ of these 44 patients had received neoadjuvant chemotherapy before surgery. The remaining six patients $(12 \%)$ enrolled in the study had locoregional recurrence that was presumed to be resectable, i.e., one focus or a limited number of hot foci of uptake demonstrated on PET/CT images. The patients were divided into two groups, one with locally advanced BC (LABC) that included 30 patients $(60 \%)$ with ipsilateral axillary $\mathrm{LN}$ metastases and the other without LABC that included 20 patients (40\%) without LN metastases. A positive PET/CT examination confirmed by pathology was considered as true-positive (TP) and otherwise as false-positive (FP). A negative imaging examination was considered to be truenegative (TN) if there was no histological nodal involvement and to be FN if there was metastatic invasion. Patients with uncontrolled diabetes mellitus, evidence of systemic metastatic disease at presentation, active infection, serious organ dysfunction, or distant metastases at the time of diagnosis of $\mathrm{BC}$ and without operation were excluded. Eligible patients were enrolled during the preoperative surgical consultation and provided informed, written consent (ethical statement n. 52.12).

PET/CT scan protocol. All patients fasted for at least 5 hours before injection of intravenous 18F-FDG. The serum glucose level was normal $(\leq 107 \mathrm{mg} / \mathrm{ml})$ in all cases. The patients then received an intravenous injection containing $370-450 \mathrm{MBq}$ of $18 \mathrm{~F}-\mathrm{FDG}$ and were hydrated with $500 \mathrm{ml}$ of intravenous saline ( $0.9 \%$ sodium chloride). Physical activity was kept to a minimum, with a rest period of $60 \mathrm{~min}$ post-injection. Images were obtained 60 minutes after administration of FDG. All examinations were performed using the PET/CT Discovery Iq system (GE Medical Systems, Fairfield, CT, USA). According to the National Electrical Manufacturers Association (NEMA), this system the highest sensitivity in the industry, up to
$22 \mathrm{cps} / \mathrm{kBq}$. The whole system is optimized for oncology practices administering ${ }^{18} \mathrm{~F}$, which accounts for nearly 94 percent of all PET procedures with a sensitivity up to $75 \mathrm{kcps}$ at $2.4 \mathrm{kBq} / \mathrm{ml}$, largest axial field-of-view coverage in the industry up to $26 \mathrm{~cm}$. For the PET/low-dose computed tomography (ldCT), a low-amperage CT scan was acquired for attenuation correction of the PET images (80 $\mathrm{mA}, 140 \mathrm{kV}$, field of view about $420-500 \mathrm{~mm}$, and a CT slice thickness of $3.75 \mathrm{~mm}$ ). The CT dose index for $1 \mathrm{dCT}$ was 4.0175 $( \pm 0.84) \mathrm{mGy}$ and the dose-length product was $473.296( \pm 161.09)$ mGy-cm. After non-enhanced CT, a total-body PET examination in the caudocranial direction from the upper thighs to the vertex was performed (3.5 min per bed). Reconstruction was performed using the novel Q Clear algorithm. The images were reviewed by a nuclear physician (A.C., B.T) and a surgical oncologist (O.C.B, P.O). The SUV and metabolic tumour volume of the target lesion(s) were measured. The PET/CT images were then reviewed by two nuclear medicine physicians on a dedicated PET/CT workstation (Advantage 4.47 GE Healthcare, Fairfield, CT, USA) that allowed visualization of the PET and CT images separately or in fusion mode in the axial, coronal, and sagittal planes. Uptake was considered pathological when an area of focal tracer uptake higher than the background was visually detected. The maximum SUV $\left(\mathrm{SUV}_{\max }\right)$ values were also determined and considered, but no absolute cut-off value was used for the diagnosis. In cases of disagreement between the readers, the patients were re-examined and a consensus was reached. The FDG uptake in the primary tumour (SUV T) and LNs (SUV LN) was semiquantitatively analyzed using the $\operatorname{SUV}_{\text {max }}(\mathrm{g} / \mathrm{ml})$, which was calculated based on the measured activity, decay-correction of the administered dose, and patient weight (Figure 1). When calculating the SUV LN, the axillary LN showing the highest SUV within the whole axillary space was selected. The NT ratio was calculated by dividing the SUV LN by the SUV T (19). In case of mild-low $18 \mathrm{~F}$ FDG uptake, the co-registered CT was used for the creation and contour of the regions of interest. 
Classification of groups and staging. The size of the breast tumour was measured, and the tumours were classified according to the American Joint Committee on Cancer (8th edition) staging criteria, i.e., T1a-b $(<10 \mathrm{~mm}), \mathrm{T} 1 \mathrm{c}(11-20 \mathrm{~mm}), \mathrm{T} 2(21-50 \mathrm{~mm})$, or T3 $(>50 \mathrm{~mm})(20)$. The number, maximum size, and nuclear grade of the involved invasive $\mathrm{BC}$ and axillary $\mathrm{LN}$ metastases were also examined by histopathology. Microscopic examination of the resected BCs and LNs was used as a reference to evaluate the ability of $18 \mathrm{~F}-\mathrm{FDG}$ PET/CT to detect the primary tumour and axillary metastases.

The intrinsic BC subtypes were identified according to the clinicopathological criteria recommended by the 2013 St. Gallen International Expert Consensus Report (21). The patients were categorized based on the receptor status of their primary tumour as follows: luminal A (oestrogen receptor-positive [OR+] or progesterone receptor-positive $[\mathrm{PR}+]$ and HER2-); luminal $\mathrm{B}$ HER 2- (OR+, HER2-, and at least one of Ki-67 "high" or PR "negative or low"); luminal B HER2+ (OR+, HER2 overexpressed or amplified, any Ki-67 value, any PR); HER2 (OR- or PR- and HER2+), or basal (OR- or PR- and HER2-). Tumours were considered HER2-positive only if they were scored as $3+$ by immunohistochemistry (IHC; strong, complete membrane-staining in $>10 \%$ of cancer cells) or showed HER2 amplification (ratio $>2$ ) using fluorescence in situ hybridization (FISH). In the absence of positive FISH data, tumours scored as $2+$ on IHC were considered negative for HER2. Tumours were also classified as luminal or nonluminal according to hormone receptor expression. Furthermore, a useful surrogate definition was developed to distinguish the pathological characterization of steroid hormone receptor status and the threshold value for "high Ki-67" based on a combination of OR $\geq 50 \%$, PR $\geq 20 \%$, and $\mathrm{Ki}-67$ status $\geq 20 \%$, in order to determine whether some variables could be considered independently associated with $18 \mathrm{~F}-\mathrm{FDG}$ uptake without a requirement for molecular diagnostics (22). The frequencies of the patients' stages and those of short-term development of remote metastasis in the non$\mathrm{LABC}$ and $\mathrm{LABC}$ groups are given in percentages. Furthermore, the prognostic impact of the level of SUV in the tumours was explored for various cut-off values to compare the biological characteristics and baseline risk of $\mathrm{BC}$ pre-therapeutically.

Endpoints and statistical analysis. The diagnostic performance of 18F-FDG PET/CT in detecting primary or recurrent LN metastases was analyzed based on the calculation of sensitivity $(\mathrm{TP} /[\mathrm{TP}+\mathrm{FN}])$, specificity (TN/[TN+FP]), PPV (TP/[TP+FP]), and NPV $(\mathrm{TN} /[\mathrm{TN}+\mathrm{FN}])$. The overall accuracy was calculated as the percentage of all TP and TN cases out of the total number of cases (23). All statistical analyses were performed using IBM SPSS version 23 software (IBM Corp., Armonk, NY, USA). The independent $t$-test, chi-square test, analysis of variance, and Spearman's rank correlation coefficient were used to establish the correlation between diagnostic performance defined by all metabolic parameters (SUV T, SUV LN, NT ratio) and clinicopathological variables. The sensitivity, specificity, PPV, and NPV of 18F-FDG PET/CT imaging for primary invasive $\mathrm{BC}$ and axillary LN staging were analyzed using standard statistical analyses. Means, standard deviations (SDs), and 95\% confidence intervals were calculated for all the quantitative variables. PET/CT parameters, stage I-III disease, and tumour characteristics across biological profiles were compared between the non-LABC and LABC groups using the $t$-test, and $p$-values $<0.05$ were considered statistically significant. Numeric data are expressed as the mean \pm SD Receiver-operating characteristic (ROC) curve analysis was performed to identify an optimal cut-off for the primary tumour (SUV T) and nodal SUVmax (SUV LN) for prediction of axillary metastasis and to determine the diagnostic utility of the NT ratio in all patients. The area under the curve ranges from 0.5 (indicating a test with no information) to 1.0 (indicating a perfect test).

\section{Results}

Patient demographics and tumour characteristics. Data were available for 44 patients with newly diagnosed BC and for 6 with locoregional recurrence after previous breast-conserving treatment or mastectomy, all of whom underwent 18F-FDG $\mathrm{PET} / \mathrm{CT}$ for preoperative staging. The median patient age was 57.4 (range $=34-88$ years). The median tumour size was $2.6 \mathrm{~cm}$ (range $=0.5-8 \mathrm{~cm}$ ). Classifying the patients according to histological type, $46(92 \%)$ had invasive ductal carcinoma and $4(8 \%)$ had invasive lobular carcinoma. Thirty percent of the tumours were scored as grade $1,48 \%$ as grade 2 , and $22 \%$ as grade 3 . The incidence of luminal and non-luminal tumours was $90 \%$ and $10 \%$, respectively. The majority of patients $(n=21,42 \%)$ had luminal A tumours, and the remaining patients had luminal $\mathrm{B}(\mathrm{n}=22,44 \%)$, HER2positive luminal B $(n=2,4 \%)$, basal $(n=4,8 \%)$, or nonluminal HER2-positive $(\mathrm{n}=1,2 \%)$ tumours. OR $\geq 50 \%$ was positive in $42(84 \%)$ of 50 tumours and PR $\geq 20 \%$ was positive in $29(58 \%)$ of 50 tumours. Overexpression of cerbB-2 was found in 3 tumours $(6 \%)$. Twenty-eight patients $(56 \%)$ had high Ki-67 expression $(\geq 20 \%)$. Twenty $(40 \%)$ of the 50 patients were staged as pN0, and $30(60 \%)$ had ipsilateral axillary LN metastases according to the gold standard. $\mathrm{N}$ stage was categorized by the staging system of the American Joint Committee on Cancer (8th edition): 15 patients $(30 \%)$ were in $\mathrm{N}$ stage $1,6(12 \%)$ in $\mathrm{N}$ stage 2 , and $9(18 \%)$ in $\mathrm{N}$ stage 3 . There were 14 patients $(28 \%)$ in stage I, $18(36 \%)$ in stage II, and $18(36 \%)$ in stage III. At the time of analysis, one patient had died during a median follow-up of 13.5 (range=4-29 months). Forty-two (92\%) of the 50 patients were disease-free and $4(8 \%)$ had recurrence of systemic disease (lung metastases in 2 and bone metastases in 2), of which $3(75 \%)$ were in the LABC group. The characteristics of the study participants are listed in Table I.

Analysis of PET features and clinicopathological factors. Axillary LN involvement was detected on pathologic examination in 30 patients $(60 \%)$ who had total axillary dissection. FDG-PET was positive in the axilla in 28 cases (56\%) and negative in $22(44 \%)$. Twenty-six $(92.8 \%)$ of the 28 axillary LN-positive results were TP and 2 (7.2\%) were FP. Four $(18.1 \%)$ of the 22 axillary LN-negative results were FN and $18(81.8 \%)$ were TN. The FN rate was $13 \%(4 / 30)$ and the FP rate was $10 \%(2 / 20)$. The sensitivity, specificity, PPV, and NPV of FDG PET/CT for detection of axillary LN metastases overall was $87 \%, 90 \%, 93 \%$, and $82 \%$, respectively. The diagnostic accuracy was $88 \%$ (Table II). 
Table I. Patients and tumour characteristics.

\begin{tabular}{|c|c|c|}
\hline Variables & Number $=50$ & $(\%)$ \\
\hline \multicolumn{3}{|c|}{ Tumor invasive size $(\mathrm{cm})$} \\
\hline$\leq 2$ & 23 & $(46)$ \\
\hline $2<$ & 27 & $(54)$ \\
\hline \multicolumn{3}{|c|}{ Tumour classification } \\
\hline $\mathrm{T} 1$ & 23 & (46) \\
\hline $\mathrm{T} 2$ & 20 & (40) \\
\hline $\mathrm{T} 3$ & 5 & $(10)$ \\
\hline $\mathrm{T} 4$ & 2 & (4) \\
\hline \multicolumn{3}{|l|}{ Histology } \\
\hline IDC & 46 & $(92)$ \\
\hline ILC & 4 & (8) \\
\hline \multicolumn{3}{|c|}{ Nuclear grade } \\
\hline 1 & 15 & $(30)$ \\
\hline 2 & 24 & $(48)$ \\
\hline 3 & 11 & $(22)$ \\
\hline \multicolumn{3}{|c|}{ Nodal metastasis } \\
\hline Negative & 20 & $(40)$ \\
\hline Positive & 30 & $(60)$ \\
\hline \multicolumn{3}{|c|}{ Lymph node classification } \\
\hline No & 20 & $(40)$ \\
\hline N1 & 15 & $(30)$ \\
\hline $\mathrm{N} 2$ & 6 & $(12)$ \\
\hline N3 & 9 & $(18)$ \\
\hline \multicolumn{3}{|c|}{ Pathological stage } \\
\hline I & 14 & $(28)$ \\
\hline II & 18 & (36) \\
\hline III & 18 & $(36)$ \\
\hline \multicolumn{3}{|c|}{ Estrogen receptor (ER) } \\
\hline $50>$ & 8 & (16) \\
\hline $50 \leq$ & 42 & $(84)$ \\
\hline \multicolumn{3}{|c|}{ Progesterone receptor $(\mathrm{PR})$} \\
\hline $20>$ & 21 & $(42)$ \\
\hline $20 \leq$ & 29 & $(58)$ \\
\hline \multicolumn{3}{|l|}{$\mathrm{Ki}-67$ index } \\
\hline $20>$ & 22 & $(44)$ \\
\hline $20 \leq$ & 28 & $(56)$ \\
\hline \multicolumn{3}{|c|}{ c-erbB-2 (HER2) } \\
\hline 0 & 33 & $(66)$ \\
\hline $1+$ & 8 & (16) \\
\hline $2+$ & 6 & $(12)$ \\
\hline $3+$ & 3 & $(6)$ \\
\hline \multicolumn{3}{|c|}{ Breast cancer subtype } \\
\hline Lum A & 21 & $(42)$ \\
\hline Lum B- & 22 & (44) \\
\hline Lum B+ & 2 & (4) \\
\hline HER 2 & 1 & (2) \\
\hline Basal & 4 & $(8)$ \\
\hline \multicolumn{3}{|c|}{ Breast cancer Profile } \\
\hline Lum & 45 & $(90)$ \\
\hline Not Lum & 5 & (10) \\
\hline \multicolumn{3}{|c|}{ Quality of tumor } \\
\hline Primary & 44 & $(88)$ \\
\hline Recurrent & 6 & (12) \\
\hline
\end{tabular}

18F-FDG uptake was lower for all parameters in invasive lobular lesions (SUV T, 4.1 \pm 2.8 ; SUV LN, 1.8 \pm 2.6 ) than in invasive ductal lesions (SUV T, 4.4 2.9; SUV LN, 2.4 \pm 3.5 ),
Table II. Diagnostic performance of 18 F-FDG PET/CT in axillary lymph node staging.

\begin{tabular}{lcc}
\hline Diagnostic parameters & \multicolumn{2}{c}{ 18F-FDG } \\
\cline { 2 - 3 } & No & $\%$ \\
\hline Sensitivity (\%) & $26 / 30$ & 87 \\
Specificity (\%) & $18 / 20$ & 90 \\
Overall Accuracy & $44 / 50$ & 88 \\
Positive-predictive value & $26 / 28$ & 93 \\
Negative-predictive value & $18 / 22$ & 82 \\
\hline
\end{tabular}

but no statistical analysis was performed because of the small number of cases.

The average SUV $\mathrm{T}$ in the 50 patients was $4.3 \pm 2.9$ (range $=0.9-13.5$ ) and the mean SUV LN was $2.3 \pm 3.4$ (range $=0.1-14.6)$. There were no significant differences in either volumetric parameter (SUV T, 5.0 $\pm 3.3 v s .3 .7 \pm 2.2$; SUV LN, $2.5 \pm 3.2 v s .2 .2 \pm 3.7$ ) for tumours measuring more or less than $2 \mathrm{~cm}$ or according to T stage $(p>0.05)$.

With regard to the tumour nuclear grade and its components, the mean SUV T was significantly different between the grade $1(3.3 \pm 1.8)$, grade $2(4.5 \pm 2.9)$, and grade $3(5.8 \pm 3.3)$ tumour groups $(p=0.05$; correlation coefficient, $\mathrm{R} 2=0.3$ ). Moreover, the mean SUV LN was significantly higher in the grade 3 lesions $(4.3 \pm 5.1)$ than in the grade $1-2$ lesions $(1.8 \pm 2.6 ; p<0.001)$, as were the number of positive LNs $(7.1 \pm 9.7$ vs. $2.6 \pm 3.8 ; p<0.001)$ and the Ki-67 index $(38.8 \pm 21.7$ vs. $17.6 \pm 10.0 ; p<0.001)$. Specifically, the mean quantitative expression of OR $(54.0 \pm 44.2 v s .82 .6 \pm 25.3$; $p=0.001)$ and PR $(15.0 \pm 32.4 v s .58 .8 \pm 38.0 ; p=0.001)$ tended to be lower in the grade 3 group.

In relation to the above findings, considering the mean quantitative expression of OR (76.3 \pm 32.2$)$, PR $(49.2 \pm 40.9)$, and Ki67 (22.3 \pm 15.8$)$, the bivariate analysis did not show a significant interaction between SUV T and OR $(p>0.05$; correlation coefficient, $\left.\mathrm{R}^{2}=-0.09\right)$ but showed that the SUV T was inversely proportional to $\mathrm{PR}(p=0.036$; correlation coefficient, $\left.\mathrm{R}^{2}=-0.3\right)$ and directly proportional to $\mathrm{Ki}-67$ ( $p=0.027$; correlation coefficient, $\mathrm{R}^{2}=0.3$ ). Furthermore, the bivariate analysis for SUV LN and the same variables showed an inverse interaction with $\mathrm{OR}$ ( $p=0.004$; correlation coefficient, $\left.\mathrm{R}^{2}=-0.4\right)$ and $\mathrm{PR}\left(p=0.05\right.$; correlation coefficient, $\left.\mathrm{R}^{2}=-0.3\right)$, and a directly proportional interaction with the number of metastatic LNs ( $p=0.01$; correlation coefficient, $\mathrm{R}^{2}=0.4$; (Table III).

According to the threshold values applied in this study, there was no significant difference in the SUV T between the ORpositive $(\leq 50 \%)$ group and the OR-negative $(\geq 50 \%)$ group $(4.2 \pm 2.8$ vs. $5.1 \pm 3.5 ; p>0.05)$ or between the PR-positive $(\leq 20 \%)$ group and PR-negative $(\geq 20 \%)$ group $(3.7 \pm 2.5$ vs. $5.3 \pm 3.1 ; p>0.05)$. However, the mean SUV LN was significantly 
Table III. Correlations between mean values of clinicopathological parameters and SUV T/SUV N states.

\begin{tabular}{lcccrrr}
\hline Variables & $($ Mean \pm SD $\%)$ & $\begin{array}{c}\text { Pearson Correlation } \\
\text { Coefficient }\end{array}$ & $p$-Value & (Mean \pm SD $\%)$ & $\begin{array}{c}\text { Pearson Correlation } \\
\text { Coefficient }\end{array}$ & $\begin{array}{c}p \text {-Value } \\
\text { SUV T }\end{array}$ \\
No. of involved nodes & $4.38 \pm 2.92$ & & & SUV N & $2.37 \pm 3.47$ & \\
ER & $3.62 \pm 5.85$ & 0.180 & 0.22 & $3.62 \pm 5.85$ & 0.343 & 0.015 \\
PR & $76.36 \pm 32.2$ & -0.097 & 0.51 & $76.36 \pm 32.2$ & -0.403 & 0.004 \\
Ki-67 & $49.20 \pm 40.90$ & -0.307 & 0.036 & $49.20 \pm 40.90$ & -0.270 \\
\hline
\end{tabular}

higher in OR-negative tumours $(5.5 \pm 5.3 v s .1 .7 \pm 2.7 ; p=0.001)$ and PR-negative tumours ( $3.3 \pm 4.0$ vs. $1.6 \pm 2.8 ; p=0.014)$. Furthermore, the NT ratio differed considerably between ORpositive and OR-negative cases $(0.38 \pm 0.45$ vs. $1.05 \pm 1.54$ $p=0.003)$, while PR negativity was associated with a larger tumour size $(3.3 \pm 2.1$ vs. $2.2 \pm 1.4 \mathrm{~cm} ; p=0.0016)$ and involvement of more nodes ( $5 \pm 7.8 v s .2 .5 \pm 3.6 ; p=0.006)$.

When categorized as $\leq 20 \%$ and $>20 \%$, the Ki-67 index showed no correlation with SUV T $(3.3 \pm 2.0$ vs. 5.2 \pm 3.3 ; $p>0.05)$, but in the event of positivity $(>20)$, the mean SUV LN was significantly higher $(2.9 \pm 4.0 v s .1 .6 \pm 2.4 ; p=0.048)$ and the tumour size was larger $(3.1 \pm 1.9 v s .2 .0 \pm 1.4 \mathrm{~cm} ; p=0.045)$ than in pathological lesions with a Ki-67 index $\leq 20$. The mean quantitative expression of OR- (70.5 \pm 35.3 vs. 83.7 \pm 26.8 ; $p=0.038)$, and PR- (35.5 \pm 39.7 vs. $66.6 \pm 36.11 ; p=0.006)$ also differed significantly according to Ki-67 status $(>20 \%)$.

With regard to c-erbB-2 status, the mean SUV T $(4.7 \pm 3.0 \mathrm{vs}$. $4.3 \pm 2.9 ; p>0.05)$ and SUV LN (1.4 \pm 0.7 vs. $2.4 \pm 3.5 ; p>0.05)$ were not significantly different between the tumour groups with scores of $2+$ and $3+$ or between those with scores 0 and $1+$. However, the mean quantitative PR- expression tended to be lower in the HER2+ group $(1.0 \pm 1.7 v s .52 .2 \pm 40.2 ; p=0.001)$.

There were no statistically significant differences in the SUV $\mathrm{T}$ between the tumour groups with and without metastatic LNs $(4.8 \pm 2.8 v s .3 .7 \pm 3.0 ; p>0.05)$. Furthermore, the mean SUV LN $(3.6 \pm 4$ vs. $0.5 \pm 0.7 ; p<0.001)$ and NT ratios $(0.69 \pm 0.88 v s .0 .20 \pm 0.31 ; p=0.05)$ were higher in the node-positive group than in the node-negative group.

There was no significant difference in the SUV T for stage I-III tumours $(3.2 \pm 1.9 v s .4 .2 \pm 3.2 v s .5 .3 \pm 3.0 ; p>0.05)$ or between the SUV LN (1.2 \pm 3.8 vs. $2.6 \pm 3.4$ vs. $2.9 \pm 3.2$; $p>0.05)$ and the respective categories. Nevertheless, the mean NT ratios were significantly different in stages I-III (0.07 \pm 0.09 vs. $0.56 \pm 0.55$ vs. $0.72 \pm 1.02 ; p=0.048)$.

There were no critical differences in the SUV T between the five molecular subtypes of BC $(p>0.05)$, but the mean SUV LN was significantly higher in triple-negative (OR/PR-/HER2-) tumours than in the others $(5.9 \pm 6.1$ vs. $2.0 \pm 3.1$; $p=0.008)$. At the same time, the SUV LN was significantly lower in luminal A tumours $(1.7 \pm 2.4 v s .2 .9 \pm 4.0 ; p=0.04)$ than in the other subtypes. Moreover, the probability of a higher SUV LN appeared to be stronger in patients with nonluminal tumours than in those with luminal tumours $(4.9 \pm 5.7$ vs. 2.0 \pm 3.1$)$; however, the difference was not statistically significant $(p=0.08)$.

In summary, the mean SUV T and SUV LN were significantly higher in the group with locoregional recurrence than in the group without $(6.1 \pm 6.0 \mathrm{vs} .4 .2 \pm 2.7, p=0.01$ and $7.0 \pm 5.7 \mathrm{vs}$. $1.7 \pm 2.5, p<0.001$, respectively). There was also a marked difference in the mean NT ratio between cases with and without local relapse $(0.77 \pm 0.04$ vs. $0.46 \pm 0.75 ; p=0.01)$ and in the number of positive nodes involved $(7.5 \pm 11.4$ vs. 3.0 \pm 4.6 ; $p=0.007)$. Correlations between the clinicopathological parameters and the SUV T, SUV LN, and NT ratio are shown in Table IV. The results on further pathways and crosstalk between the biological features are summarized in Table V and Figure 2.

Patients' prognosis and cut-off values for metabolic parameters. A ROC curve analysis was also performed to identify which metabolic parameters (SUV T, SUV LN, NT ratio) better reflected the probability of axillary metastasis on final pathology. Our hypothesis was that nodal status would still be a potential signature of the intrinsic biological properties of a primary tumour.

The results indicated that a SUV T of 3.1 was the optimal cut-off value for predicting progression of lymphatic disease (sensitivity, 70\%; specificity, 60\%; area under the curve, 0.639; standard error, 0.0844); however, this finding was not statistically significant ( $p=0.14$; Figure 3 ). Furthermore, the analysis revealed that a SUV LN of 0.99 (sensitivity, 77\%; specificity, $84 \%$; area under the curve, 0.869; standard error, $0.052 ; p<0.001$; Figure 4$)$ and an NT ratio of 0.12 (sensitivity, 80\%; specificity, 70\%; area under the curve, 0.814; standard error, $0.068 ; p<0.001)$ were the best threshold values for detecting nodal malignancy (Figure 5).

\section{Discussion}

The role of $18 \mathrm{~F}-\mathrm{FDG}$ PET/CT in the planning of management of patients with $\mathrm{BC}$ is increasing (24). The prognosis and therapeutic decision-making are based primarily on precise data on the real extent of the disease, 
Table IV. Correlations between clinicopathological parameters and the levels of SUV T, SUV N, and NT ratio.

\begin{tabular}{|c|c|c|c|c|c|c|}
\hline Variables & $\begin{array}{c}\text { SUV T } \\
(\text { Mean } \pm \text { SD } \%)\end{array}$ & $p$-Value & $\begin{array}{c}\text { SUV LN } \\
(\text { Mean } \pm \text { SD } \%)\end{array}$ & $p$-Value & $\begin{array}{c}\text { NT Ratio } \\
(\text { Mean } \pm \text { SD } \%)\end{array}$ & $p$-Value \\
\hline \multicolumn{7}{|c|}{ Tumor invasive size $(\mathrm{cm})$} \\
\hline$\leq 2$ & $3.7 \pm 2.2$ & \multirow{2}{*}{0.16} & $2.2 \pm 3.7$ & \multirow{2}{*}{0.75} & $0.43 \pm 0.91$ & \multirow{2}{*}{0.69} \\
\hline $2<$ & $5.0 \pm 3.3$ & & $2.5 \pm 3.2$ & & $0.53 \pm 0.52$ & \\
\hline \multicolumn{7}{|l|}{ Histology } \\
\hline IDC & $4.4 \pm 2.9$ & \multirow[t]{2}{*}{$>0.05$} & $2.4 \pm 3.5$ & \multirow[t]{2}{*}{$>0.05$} & $0.48 \pm 0.75$ & \multirow[t]{2}{*}{$>0.05$} \\
\hline ILC & $4.1 \pm 2.8$ & & $1.8 \pm 2.6$ & & $0.50 \pm 0.36$ & \\
\hline \multicolumn{7}{|l|}{ Nuclear grade } \\
\hline $1-2$ & $4.0 \pm 2.4$ & \multirow[t]{2}{*}{0.05} & $1.8 \pm 2.6$ & \multirow[t]{2}{*}{0.001} & $0.50 \pm 079$ & \multirow[t]{2}{*}{$>0.05$} \\
\hline 3 & $5.8 \pm 3.3$ & & $4.3 \pm 5.1$ & & $0.38 \pm 0.29$ & \\
\hline \multicolumn{7}{|c|}{ Nodal metastasis } \\
\hline Negative & $3.7 \pm 3.0$ & \multirow[t]{2}{*}{0.93} & $0.5 \pm 0.7$ & \multirow[t]{2}{*}{0.001} & $0.20 \pm 0.31$ & \multirow[t]{2}{*}{0.058} \\
\hline Positive & $4.8 \pm 2.8$ & & $3.6 \pm 4.0$ & & $0.69 \pm 0.88$ & \\
\hline \multicolumn{7}{|c|}{ Pathological stage } \\
\hline I & $3.2 \pm 1.9$ & \multirow[t]{3}{*}{0.15} & $1.2 \pm 3.8$ & \multirow[t]{3}{*}{0.38} & $0.07 \pm 0.09$ & \multirow[t]{3}{*}{0.048} \\
\hline II & $4.2 \pm 3.2$ & & $2.6 \pm 3.4$ & & $0.56 \pm 0.55$ & \\
\hline III & $5.3 \pm 3.0$ & & $2.9 \pm 3.2$ & & $0.72 \pm 1.02$ & \\
\hline \multicolumn{7}{|c|}{ Estrogen receptor (ER) } \\
\hline $50>$ & $5.1 \pm 3.5$ & \multirow[t]{2}{*}{$>0.05$} & $5.5 \pm 5.3$ & \multirow[t]{2}{*}{0.001} & $1.05 \pm 1.54$ & \multirow[t]{2}{*}{0.003} \\
\hline $50 \leq$ & $4.2 \pm 2.8$ & & $1.7 \pm 2.7$ & & $0.38 \pm 0.45$ & \\
\hline \multicolumn{7}{|c|}{ Progesterone receptor (PR) } \\
\hline $20>$ & $5.3 \pm 3.1$ & \multirow[t]{2}{*}{$>0.05$} & $3.3 \pm 4.0$ & 0.014 & $0.63 \pm 0.98$ & $>0.05$ \\
\hline $20 \leq$ & $3.7 \pm 2.5$ & & $1.6 \pm 2.8$ & & $0.38 \pm 0.50$ & \\
\hline $\mathrm{Ki}-67$ index & & & & & & \\
\hline $20>$ & $3.3 \pm 2.0$ & $>0.05$ & $1.6 \pm 2.4$ & 0.048 & $0.44 \pm 0.53$ & $>0.05$ \\
\hline $20 \leq$ & $5.2 \pm 3.3$ & & $2.9 \pm 4.0$ & & $0.52 \pm 0.88$ & \\
\hline c-erbB-2 (HEF & & & & & & \\
\hline $0-1$ & $4.3 \pm 2.9$ & $>0.05$ & $2.4 \pm 3.5$ & $>0.05$ & $0.49 \pm 0.76$ & $>0.05$ \\
\hline $2-3$ & $4.7 \pm 3.0$ & & $1.4 \pm 0.6$ & & $0.39 \pm 0.22$ & \\
\hline Breast cancer & & & & & & \\
\hline Basal & $6.8 \pm 2.2$ & 0.56 & $5.9 \pm 6.12$ & 0.008 & $0.44 \pm 0.60$ & 0.98 \\
\hline Non-basal & $4.2 \pm 2.9$ & & $2.0 \pm 3.07$ & & $0.48 \pm 0.75$ & \\
\hline Lum A & $3.3 \pm 2.0$ & 0.11 & $1.6 \pm 2.4$ & 0.048 & $0.44 \pm 0.53$ & 0.46 \\
\hline Not Lum A & $5.2 \pm 3.3$ & & $2.9 \pm 4.0$ & & $0.52 \pm 0.88$ & \\
\hline Lum & $4.2 \pm 2.9$ & 0.75 & $2.09 \pm 3.1$ & 0.08 & $0.48 \pm 0.75$ & 0.81 \\
\hline Not Lum & $5.4 \pm 3.2$ & & $4.91 \pm 5.7$ & & $0.48 \pm 0.49$ & \\
\hline Quality of tum & & & & & & \\
\hline Primary & $4.2 \pm 2.7$ & 0.01 & $1.7 \pm 2.5$ & 0.001 & $0.46 \pm 0.75$ & 0.01 \\
\hline Recurrent & $6.1 \pm 6.0$ & & $7.0 \pm 5.7$ & & $0.77 \pm 0.04$ & \\
\hline
\end{tabular}

which is directly related to several biological parameters and metastatic involvement of locoregional LNs. Involvement of these nodes is accepted as the most reliable predictor of disease recurrence and survival (25). However, despite being a non-invasive imaging tool, the efficiency of PET/CT in evaluating locoregional nodal status has not yet been welldefined in clinical practice, and its sensitivity for detection of axillary metastases remains low in the range of $37-85 \%$ depending on the axillary tumour burden and affinity of the BC for 18F-FDG (26-28).

This functional diagnostic procedure may help identify patients with a high axillary LN burden who could move directly to ALND and not require the additional step of SLNB (29). However, an FN scan in the evaluation of axillary disease is mainly secondary to smaller and fewer tumour-positive LNs than TP cases (28). Some recent studies in which IHC and multistep sectioning were used to increase the rate of detection of axillary micrometastases with ALND/SLNB have cast doubt on the role of $18 \mathrm{~F}-\mathrm{FDG}$ $\mathrm{PET} / \mathrm{CT}$ in the axillary staging of BC. In these studies, PET proved to have poor sensitivity, ranging from $20-43 \%$ (23, 30). However, any discussion concerning this oncological indication should take into consideration the fact that there is presently no alternative strategy to routine ALND that does not entail an intrinsic low risk of downstaging the axillary status, given that even SLNB has had a nonnegligible FN rate in almost all studies reported to date (31). This limitation of PET/CT should be analyzed in relation to 


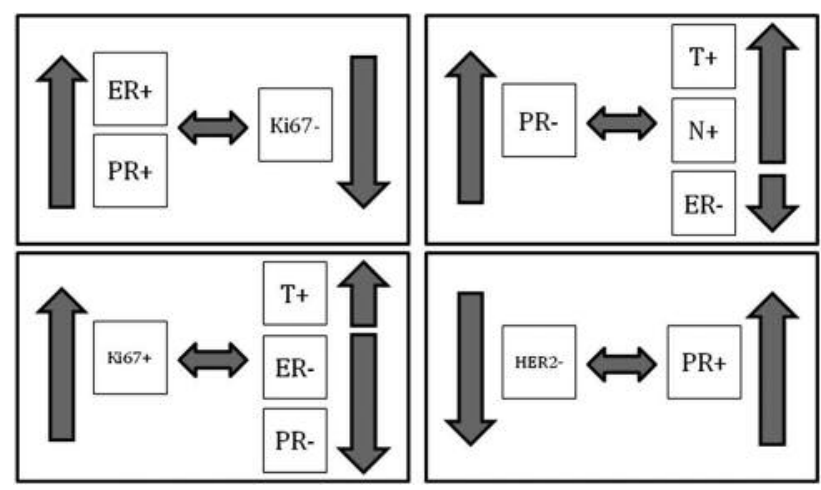

Figure 2. Biological pathways and cross-talks according to patients' characteristics.

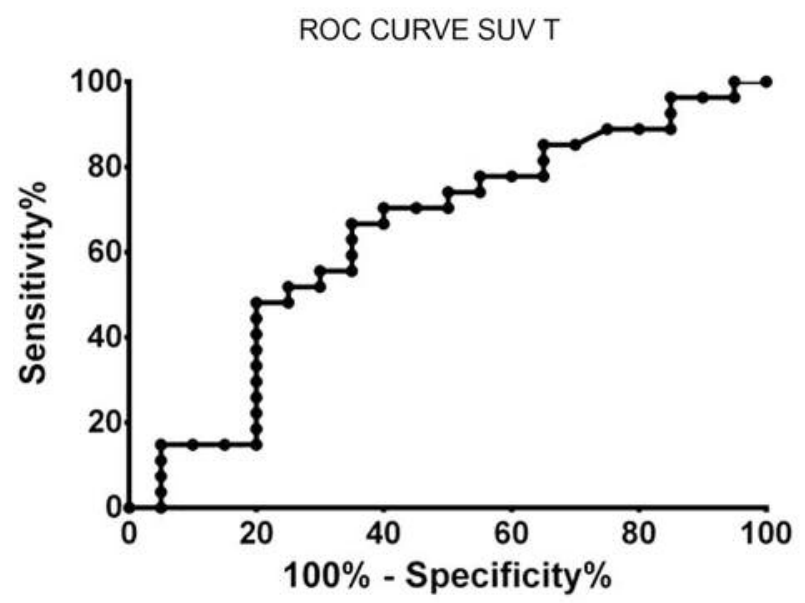

Figure 3. ROC curve analysis of the discriminative power of SUV T for the prediction of axillary node metastasis (SUV T=3.1; sensitivity (70\%); specificity (60\%); area under the curve (0.639); SE (0.0844); $p=0.14)$.

the importance of axillary metastases for the outcome in patients with BC. Limited data suggest that only a few axillary micrometastases become clinically evident during follow-up, and further analysis of these patients has demonstrated that these locoregional relapses have no major impact on overall survival (32-34).

Moreover, full-diagnostic 18F-FDG PET/CT has good overall accuracy and high specificity, and has the potential to be able to triage patients to SLNB or ALND. In patients with a high risk of axillary $\mathrm{LN}$ metastases and being a priori not candidates for SLNB, an unremarkable scan can still identify a subgroup of patients who can safely undergo SLNB instead of immediate ALND. In this context, high risk is defined as a greater than $40 \%$ probability of axillary node metastases, corresponding to primary tumours with a diameter greater than $2-3 \mathrm{~cm}$. Such an approach may extend

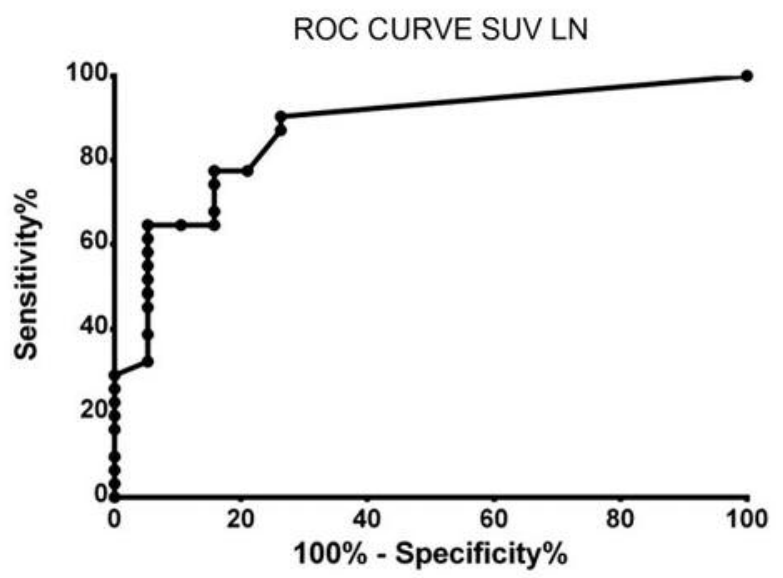

Figure 4. ROC curve analysis of the discriminative power of SUV LN for the prediction of axillary node metastasis ( $S U V N=0.99$; sensitivity (77\%); specificity (84\%); area under the curve (0.869); SE (0.052); $p<0.001)$.

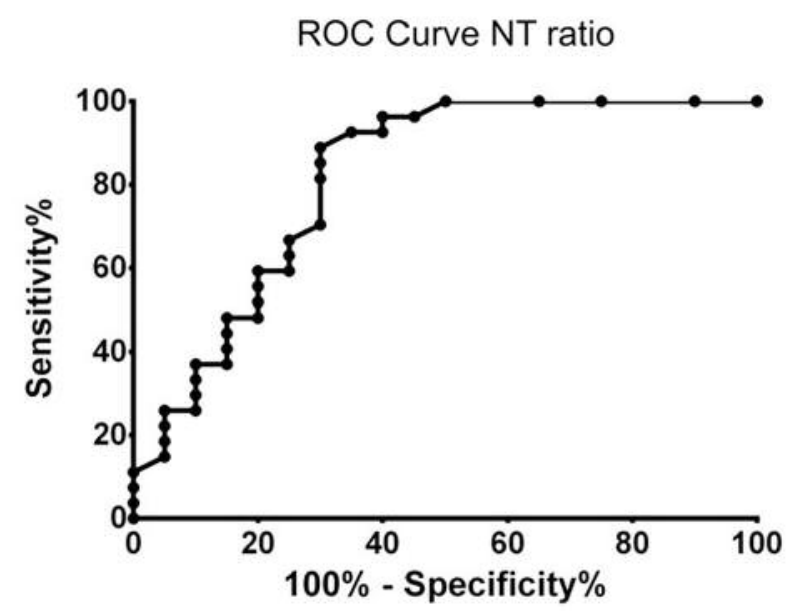

Figure 5. ROC curve analysis of the discriminative power of NT ratio for the prediction of axillary node metastasis (NT ratio 0.12; sensitivity (80\%); specificity (70\%); area under the curve (0.814); SE (0.068); $p<0.001)$.

the indication for SLNB to patients with an up to $60 \%$ risk of lymphatic metastases, corresponding to a tumour diameter of $4-5 \mathrm{~cm}$, and thus avoid the comorbidity of unnecessary ALND in a substantial proportion of patients (35).

This study shows that the specificity (90\%) and PPV (93\%) of PET/CT for detection of axillary metastases in patients with primary BC are high. Furthermore, in 13 patients with negative procedures who underwent axillary dissection based on clinical indications, the nodes were negative in 11 cases and positive in 2 . This translates into a potential 25\% (11/43) reduction in unnecessary ALND 
Table V. Correlations between clinicopathological parameters and tumor features (Student's t-test).

\begin{tabular}{|c|c|c|c|c|c|c|c|c|c|c|}
\hline Variables & $\begin{array}{c}\text { T size } \\
(\text { Mean } \pm \mathrm{SD} \%)\end{array}$ & $p$-Value & $\begin{array}{l}\text { No. of involved nodes } \\
\quad(\text { Mean } \pm \text { SD \%) }\end{array}$ & $p$-Value & $\begin{array}{c}\mathrm{ER} \\
(\text { Mean } \pm \mathrm{SD} \%)\end{array}$ & $p$-Value & $\begin{array}{c}\mathrm{PR} \\
(\text { Mean } \pm \mathrm{SD} \%)\end{array}$ & $p$-Value & $\begin{array}{c}\text { Ki-67 } \\
(\text { Mean } \pm \text { SD\%) }\end{array}$ & $p$-Value \\
\hline \multicolumn{11}{|c|}{ Nuclear grade } \\
\hline $1-2$ & $2.4 \pm 1.5$ & \multirow[t]{2}{*}{$>0.05$} & $2.6 \pm 3.8$ & \multirow[t]{2}{*}{0.001} & $82.6 \pm 25.3$ & \multirow[t]{2}{*}{0.001} & $58.8 \pm 38.0$ & \multirow[t]{2}{*}{0.001} & $17.6 \pm 10.0$ & \multirow[t]{2}{*}{0.001} \\
\hline 3 & $3.5 \pm 2.4$ & & $7.1 \pm 9.7$ & & $54.0 \pm 44.2$ & & $15.0 \pm 32.4$ & & $38.8 \pm 21.7$ & \\
\hline \multicolumn{11}{|l|}{ ER } \\
\hline $50>$ & $2.6 \pm 2.0$ & \multirow[t]{2}{*}{$>0.05$} & $4.7 \pm 10.2$ & \multirow[t]{2}{*}{$>0.05$} & - & \multirow[t]{2}{*}{-} & $10.1 \pm 28.2$ & \multirow[t]{2}{*}{0.004} & $33.5 \pm 23.9$ & \multirow[t]{2}{*}{0.026} \\
\hline $50 \leq$ & $2.7 \pm 1.8$ & & $3.4 \pm 4.7$ & & & & $50.6 \pm 38.4$ & & $20.2 \pm 13.22$ & \\
\hline \multicolumn{11}{|l|}{ PR } \\
\hline $20>$ & $3.3 \pm 2.1$ & \multirow[t]{2}{*}{0.016} & $5.0 \pm 7.8$ & \multirow[t]{2}{*}{0.006} & $61.5 \pm 41.3$ & \multirow[t]{2}{*}{0.001} & & & $29.8 \pm 18.9$ & \multirow[t]{2}{*}{0.009} \\
\hline $20 \leq$ & $2.2 \pm 1.4$ & & $2.5 \pm 3.6$ & & $87.1 \pm 17.9$ & & - & - & $16.9 \pm 10.6$ & \\
\hline \multicolumn{11}{|l|}{ Ki-67 } \\
\hline $20>$ & $2.0 \pm 1.4$ & \multirow[t]{2}{*}{0.045} & $2.7 \pm 3.8$ & \multirow[t]{2}{*}{$>0.05$} & $83.7 \pm 26.8$ & \multirow[t]{2}{*}{0.038} & $66.6 \pm 36.1$ & \multirow[t]{2}{*}{0.006} & \multirow[t]{2}{*}{-} & \multirow[t]{2}{*}{ - } \\
\hline $20 \leq$ & $3.1 \pm 1.9$ & & $4.2 \pm 7.0$ & & $70.5 \pm 35.3$ & & $35.5 \pm 39.7$ & & & \\
\hline \multicolumn{11}{|l|}{ HER2 } \\
\hline $0-1$ & $2.6 \pm 1.8$ & \multirow[t]{2}{*}{$>0.05$} & $3.7 \pm 5.9$ & \multirow[t]{2}{*}{$>0.05$} & $78.0 \pm 31.1$ & \multirow[t]{2}{*}{$>0.05$} & $52.2 \pm 40.2$ & \multirow[t]{2}{*}{0.001} & $21.3 \pm 14.7$ & \multirow[t]{2}{*}{$>0.05$} \\
\hline $2-3$ & $3.5 \pm 2.0$ & & $1.0 \pm 1.0$ & & $50.0 \pm 45.8$ & & $1.0 \pm 1.7$ & & $38.0 \pm 27.7$ & \\
\hline
\end{tabular}

procedures and associated morbidities if perioperative $\mathrm{PET} / \mathrm{CT}$ imaging is used. However, the suboptimal sensitivity and NPV and an SLNB when 18F-FDG-avid axillary nodes are absent remain important.

It seems reasonable that these strategies, when supported by the clinical use of more sophisticated biological and molecular markers available from the primary tumour, might one day abolish the need for histopathological evaluation of axillary LNs with related mapping techniques to establish the best treatment approach following surgery $(36,37)$. In this regard, the ongoing evolution of metabolic imaging represents a promising development, given that tumours with aggressive characteristics and an unfavourable prognosis show a higher degree of $18 \mathrm{~F}-\mathrm{FDG}$ uptake $(38,39)$. However, it is also known that breast carcinomas have a variable metabolic rate and that characterization of small lesions $(<0.8 \mathrm{~mm})$ is less reliable, probably because of the partial volume effect and low metabolic activity, which may also indicate inflammatory lesions (40).

Despite these limitations, some studies have found a positive relationship between the $\mathrm{SUV}_{\max }$ and tumour size (41). Nevertheless, in our study, the non-significant correlation between tumour size and SUV T/LN led us to consider that the size and metabolism of the tumour are not closely related. This discrepancy in the literature may be explained by differences in histology (necrotic or fibrotic tissue) and biology (OR and PR expression) between tumours that may influence the SUV by affecting the tumoral microenvironment. Moreover, although tumour size is an obvious marker of deep changes in cell biology and a strong predictor of survival in patients with BC, this wellestablished relationship does not appear to hold in a small subset of cancers with more aggressive phenotypes and pathways with higher risk of invasion, as shown by other researchers (42).

Several reports, including ours, have found a significant relationship between FDG uptake and pathological grade, which is attributed to the finding that less differentiated tumours with higher tumour growth rates have a higher metabolic rate (43). This finding might reflect high Glut-1 levels at the membrane and an increased level of hexokinase in the cytoplasm, which are encountered in high-grade human cancers, including BC $(11,44,45)$.

In light of the current literature, we believe that a breast mass with a high SUV may indicate the aggressiveness of $\mathrm{BC}$ at the time of initial diagnosis, as evidenced by the greater number of involved nodes, as well as the higher $\mathrm{Ki}$ 67 proliferation index in the grade 3 group in our study.

Most of the recently published studies have shown a correlation between hormone receptor status and SUV (38, $41,46)$. The results of our study confirmed a higher $18 \mathrm{~F}-$ FDG uptake in OR-negative and PR-negative tumours than in OR-positive and PR-negative tumours. The correlations were statistically significant, especially for nodal $\mathrm{SUV}_{\max }$, highlighting the prognostic significance of this combination of marked biochemical alterations of LNs to discriminate high-risk from low-risk subjects $(47,48)$. Microarray analysis has confirmed these results and identified genes associated with increased glucose use as measured by PET, suggesting that increased glucose consumption can be linked to a specific genetic signature (41). Furthermore, it is possible that improved predictive models based on PET/CT findings in patients with axillary $\mathrm{LN}$ involvement for preoperative evaluation of the chances of disease recurrence will be useful when choosing therapeutic strategies (49). In this context, adequate knowledge of the initial clinical stage 
of a breast tumour is also necessary to ensure local disease control and make decisions regarding appropriate systemic interventions, given that in the present series we were able to document a significantly higher $\mathrm{pT}$ size and positive $\mathrm{LN}$ involvement in the PR-negative subgroup. This is particularly important because evaluation of PR expression levels $\geq 20 \%$ can impact the molecular classification of BC, maximizing the number of patients classifiable as having a luminal A-like profile. In these patients, the use of cytotoxic drugs could largely be avoided, in the light of the more indolent course and better prognosis of cancer (22).

Although the Ki-67 cut-off value is controversial, it is also one of the most important prognostic markers that, when integrated with other predictive factors, aids in better assessment of patients who are at risk of adverse outcomes and in selection of optimal treatment for BC $(2,50)$. A correlation between all volumetric parameters and the Ki-67 index was found when our cohort was evaluated as a whole, with the strongest interactions occurring with the SUV LN and the mean quantitative hormonal status expression being lower in the "high Ki-67" cases. A high Ki-67 index indicates a high rate of mitosis and proliferation, and it has also been reported to be associated with the response to treatment, local recurrence, and metastasis $(51,52)$. According to our results, there is also a reverse association between Ki-67 and hormone receptor status, such that if the Ki-67 index is positive, OR/PR expression will likely be lower in the malignant tissue, in conformity of such a biological association with $\mathrm{SUV}_{\max }$ measurements. This finding would suggest that glucose metabolism is accelerated in these poorly differentiated and aggressive tumours to meet the energy demand of rapid growth. To date, no imaging modality or parameter that can predict the metastatic potential of $\mathrm{BC}$ has been identified, and 18F-FDG PET/CT may provide a non-invasive mean of assessing tumour characteristics and facilitating individualized management of cancer.

Overexpression of the c-erbB-2 oncoprotein is a wellknown contributor to tumour aggressiveness and poor prognosis, and the advent of trastuzumab, an antibody treatment targeting this receptor has been a breakthrough (53). Some studies have found a significant relationship between 18F-FDG uptake and expression of the c-erbB-2 oncogene $(54,55)$. However, in those studies, $46 \%$ of tumours were $<2 \mathrm{~cm}$ in size, which might have biased their results. No significant difference in c-erbB-2 overexpression on SUV was found in our present series or in several other studies $(38,56-58)$, suggesting that HER2 has no major influence on glycolytic pathways. However, although many pathways are regulated by these receptors and the cross-talk between these receptors are still incompletely understood, it is possible that the c-erbB2 status inversely interacts with both OR and PR in terms of 18F-FDG uptake, and may characterize their metabolic effects (58).
An increased SUV LN has been suggested to reflect intense proliferation of nodal BC cells (59). Similarly, in the LABC patients participated in this study, who were classified most commonly as stage II-III, a relatively high number of metastatic LNs was demonstrated $(6.0 \pm 6.5 ; p<0.001)$, with a significantly high SUV LN $(3.6 \pm 4.0)(p<0.001)$ and NT ratio $(0.69 \pm 0.88 ; p=0.05)$. However, it was also reported that an FN scan is necessary in the evaluation of the axillary involvement particularly because of the small size of LNs and due to limitations in the anatomical resolution of this imaging procedure which was reported to be $5-6 \mathrm{~mm}$ (26). Given that micrometastases cannot be excluded by a negative $\mathrm{PET} / \mathrm{CT}$, it is considered that the metabolic features of the primary mass should be evaluated carefully, as in our study, in order to predict an occult axillary LN metastasis. Recently, the NT ratio was introduced as a new PET/CT parameter and found to be useful in evaluating metastatic LNs in non-small cell lung cancer and BC $(19,60)$. Similarly, in our study, the mean NT ratio in the LABC group was significantly higher than that in the non-LABC group, and it is concluded that it can be used as a promising quantitative parameter for the preoperative evaluation of axillary LNs suspected to be metastatic, as well as for characterizing the different pathological stages of BC. In addition, combining the NT ratio and the SUV N, on the basis of the set cut-off values identified in the current study to predict the burden of axillary disease, may be important for minimizing FP cases. However, tumours with a low SUV, including low-grade malignancies and benign inflammatory lesions, also warrant attention, and whether the NT ratio is efficacious in patients receiving chemotherapy, endocrine therapy, and molecular targeted therapy is unclear.

Furthermore, our study confirms that the $18 \mathrm{~F}-\mathrm{FDG}$ uptake in tumours is associated with distinct immunohistochemically defined biological subtypes. According to the results of previous studies, the SUV LN is significantly higher in basal BCs than in non-basal $\mathrm{BCs}$, and with a greater difference in isolated semiquantitative values observed for the luminal A group (46, 61, 62). Basal-like tumours certainly have distinct epidemiological phenotypic and molecular features with distinct patterns of relapse and a poor prognosis, whereas among the OR-positive tumours, the luminal A type tends to show higher expression of pathways related to OR signalling and lower expression of proliferative (HER-2-related) genes, with specific consequences for the clinical outcome (63). Therefore, different oncogenes might influence the glycolytic pathway, and the resulting increase in metabolic activity is a hallmark of cancer that can be imaged using 18F-FDG PET/CT $(64,65)$. Consistent with the most recent results reported by Garcia et al, the present investigation shows a significant correlation between variability in nodal SUV and the more biologically aggressive molecular portraits, supporting the view that there is a relationship with glycolytic phenotypes (66). 
Finally, our findings suggest that PET/CT is not only effective for detection of locoregional recurrence in association with conventional imaging findings, but may also allow better characterization of lesions in patients in whom there is a strong suspicion of relapse, all correlated with a higher $18 \mathrm{~F}-\mathrm{FDG}$ uptake compared to those of the nonrecurrent group. In this clinical scenario, diagnostic functional imaging can add significant prognostic information to the restaging capabilities, given that survival of patients who develop an isolated locoregional recurrence differs significantly from that of patients who have a distant relapse. Consequently, determination of both the location and extent of recurrent disease is essential to guide therapeutic decisions and estimate the prognosis. Some authors have suggested that FDG-PET/CT can have a significant impact on subsequent therapeutic management; however, information concerning its utility for long-term prognostic stratification, when compared with conventional imaging, is limited. Therefore, accurate selection of lesions in patients who could actually benefit from use of this imaging approach appears to be important $(67,68)$.

The main limitation of our study is the relatively low number of patients in the subgroups and that all patients had undergone previous diagnostic core biopsies that removed a portion of the cancer tissue. Therefore, the overall amount of $18 \mathrm{~F}-\mathrm{FDG}$ uptake may have been reduced, resulting in lowering of the overall contrast of the lesion on PET/CT because of the partial volume effect. Moreover, classification based on steroid receptors and HER2 status is only an approximation of the underlying genotype-based BC subtype. Furthermore, the greatest drawback presently is the lack of standard methods and definitive cut-off values for calculating volumetric parameters in the literature (69-72). Finally, our findings could not be correlated with long-term disease-free survival in our patients, so the long-term prognostic value of our results is unclear.

\section{Conclusion}

$\mathrm{PET} / \mathrm{CT}$ is a reproducible, non-invasive imaging modality that is useful for evaluating a primary BC mass and its relationship with metastatic axillary LNs, allowing for a selective approach to either ALND or SLNB. The findings of this study suggest that the nodal $\mathrm{SUV}_{\text {max }}$ and NT ratio before initial treatment could be an independent prognostic factor for $\mathrm{LN}$ involvement, thus predicting tumour behaviour and guiding clinical practice. Furthermore, the systemic nature of this powerful tool enables one-stage evaluation of the whole body and subsequent treatment, and future endeavours to improve its sensitivity and specificity will enhance its diagnostic utility in the management of BC.

Our findings suggest that histological and biological criteria might be taken into account, in addition to clinical stage, to select candidates for a basal 18FDG-PET/CT study. Our SUV analysis in 50 patients showed that high tumour grade (grade 3 ), hormone receptor negativity, high Ki-67 labelling index, triple negativity, and axillary involvement are associated with increased 18F-FDG uptake. The present evidence indicates that it might be difficult to predict the potential for metastasis to the axillary LNs from the SUV in primary BC; however, the values of parameters indicating the proliferative activity and aggressiveness of cancer cells were strongly correlated with high SUV in axillary LNs with metastases. Failure to detect nodal diffusion may result from the low metabolic rate of the tumour, which is an intrinsic disease characteristic, like type and grade. In conclusion, our preliminary findings indicate that the status of molecular markers, as determined using core needle biopsies and preoperative 18F-FDG PET/CT parameters, might be used to identify high-risk BC patients. These pathological and biological factors are also known to confer a poor prognosis and probably a greater incidence of occult distant metastases. When the results of longer clinical follow-up become available for this large prospective series of patients with BC, we will investigate whether the initial SUV has a prognostic value in addition to that of the classic clinicopathological factors.

\section{Conflicts of Interest}

No benefits, in any form, have been received or will be received from any commercial party related directly or indirectly to the subject of this article.

\section{Acknowledgements}

This research project was supported by the Italian Ministry of Health.

\section{References}

1 Gradishar WJ, Anderson BO, Balassanian R, Blair SL, Burstein HJ, Cyr A, Elias AD, Farrar WB, Forero A, Giordano SH, Goetz M, Goldstein LJ, Hudis CA, Isakoff SJ, Marcom PK, Mayer IA, McCormick B, Moran M, Patel SA, Pierce LJ, Reed EC, Salerno KE, Schwartzberg LS, Smith KL, Smith ML, Soliman H, Somlo G, Telli M, Ward JH, Shead DA and Kumar R: NCCN guidelines insights breast cancer, version 1.2016. J Natl Compr Canc Netw 13: 1475-1485, 2015.

2 de Azambuja E, Cardoso F, de Castro G Jr., Colozza M, Mano MS, Durbecq V, Sotiriou C, Larsimont D, Piccart-Gebhart MJ and Paesmans M: Ki-67 as prognostic marker in early breast cancer: a meta-analysis of published studies involving 12,155 patients. Br J Cancer 96: 1504-1513, 2007.

3 Miller WR, Ellis IO, Sainsbury JR and Dixon JM: ABC of breast diseases. Prognostic factors. BMJ 309: 1573-1576, 1994.

4 Schulze T, Mucke J, Markwardt J, Schlag PM and Bembenek A: Long-term morbidity of patients with early breast cancer after sentinel lymph node biopsy compared to axillary lymph node dissection. J Surg Oncol 93: 109-119, 2006. 
5 Dees EC, Shulman LN, Souba WW and Smith BL: Does information from axillary dissection change treatment in clinically node-negative patients with breast cancer? An algorithm for assessment of impact of axillary dissection. Ann Surg 226: 279-286, 1997.

6 Gerber B, Krause A, Muleller H, Richter D, Reimer T, Makovitzky J, Herrnring C, Jeschke U, Kundt G and Friese K: Simultaneous immunohistochemical detection of tumor cells in lymph nodes and bone marrow aspirates in breast cancer and its correlation with other prognostic factors. J Clin Oncol 19: 960-997, 2001.

7 Barrett T, Choyke PL and Kobayashi H: Imaging of the lymphatic system: new horizons. Contrast Med Mol Imaging 1: 230-245, 2006.

8 Kim SJ, Kim SK, Lee ES, Ro J and Kang S: Predictive value of [18F]FDG PET for pathological response of breast cancer to neo-adjuvant chemotherapy. Ann Oncol 15(9): 1352-1357, 2004.

9 Wahl RL, Zasadny K, Helvie M, Hutchins GD, Weber B and Cody $\mathrm{R}$ : Metabolic monitoring of breast cancer chemohormonotherapy using positron emission tomography: initial evaluation. J Clin Oncol 11(11): 2101-2111, 1993.

10 Smith IC, Welch AE, Hutcheon AW, Miller ID, Payne S, Chilcott F, Waikar S, Whitaker T, Ah-See AK, Eremin O, Heys SD, Gilbert FJ and Sharp PF: Positron emission tomography using $[18 \mathrm{~F}]$ fluorodeoxy-D-glucose to predict the pathologic response of breast cancer to primary chemotherapy. J Clin Oncol 18(8): 1676-1688, 2000

11 Berriolo-Riedinger A, Touzery C, Riedinger JM, Toubeau M, Coudert B, Arnould L, Boichot C, Cochet A, Fumoleau P and Brunotte F: [18F]-FDG-PET predicts complete pathological response of breast cancer to neoadjuvant chemotherapy. Eur J Nucl Med Mol Imaging 34(12): 1915-1924, 2007.

12 Ogino K1, Nakajima M, Kakuta M, Hayashi M, Yamaguchi S, Tsuchioka T, Kubota K, Sakamoto S and Kato H: Utility of FDG-PET/CT in the evaluation of the response of locally advanced breast cancer to neoadjuvant chemotherapy. Int Surg 99(4): 309-318, 2014.

13 Alvarez JV, Belka GK, Pan T-C, Chen C-C, Blankemeyer E, Alavi A, Karp JS and Chodosh LA: Oncogene pathway activation in mammary tumors dictates FDG-PET uptake. Cancer Res 74: 7583-7598, 2014

14 Gulec SA, Mountcastle TS, Frey D, Cundiff JD, Mathews E, Anthony L, O'Leary JP and Boudreaux JP: Cytoreductive surgery in patients with advanced stage carcinoid tumors. Am Surg 68: 667-671, 2002.

15 Touzios JG, Kiely GM, Pitt SC, Rilling WS, Quebbeman EJ, Wilson SD and Pitt HA: Neuroendocrine hepatic metastases: Does aggressive management improve survival? Ann Surg 241: 776-783, 2005.

16 Fazun M, Terzi C, Sokmen S, Unek T and Haciyanli M: Potentially curative resection for locoregional recurrence of colorectal cancer. Surg Today 34: 907-912, 2004.

17 Orsaria P, Chiaravalloti A, Fiorentini A, Pistolese C, Vanni G, Granai AV, Varvaras D, Danieli R, Schillaci O, Petrella G and Buonomo OC: PET probe-guided surgery in patients with breast cancer: Proposal for a methodological approach. In Vivo 31(1): 101-110, 2017.

18 Fletcher JW, Djulbegovic B, Soares HP. Siegel BA, Lowe VJ, Lyman GH, Coleman RE, Wahl R, Paschold JC, Avril N, Einhorn LH, Suh WW, Samson D, Delbeke D, Gorman M and
Shields AF: Recommendations on the use of 18F-FDG PET in oncology. J Nucl Med 49: 480-508, 2008.

19 Cerfolio RJ and Bryant AS: Ratio of the maximum standardized uptake value on FDG-PET of the mediastinal (N2) lymph nodes to the primary tumor may be a universal predictor of nodal malignancy in patients with non-small cell lung cancer. Ann Thorac Surg 83: 1826-1830, 2007.

20 Amin MB, Edge S, Greene F, Byrd DR, Brookland RK, Washington MK, Gershenwald JE, Compton CC, Hess KR, Sullivan DC, Jessup JM, Brierley JD, Gaspar LE, Schilsky RL, Balch CM, Winchester DP, Asare EA, Madera M, Gress DM and Meyer LR: American Joint Committee on Cancer (AJCC). Cancer staging manual. Eighth edition. Springer, New York, 2017.

21 Goldhirsch A, Winer EP, Coates AS, Gelber RD, Piccart-Gebhart M, Thürlimann B, Senn HJ and Panel members: Personalizing the treatment of women with early breast cancer: highlights of the st gallen international expert consensus on the primary therapy of early breast cancer. Ann Oncol 24(9): 2206-2223, 2013.

22 Maisonneuve P, Disalvatore D, Rotmensz N, Curigliano G, Colleoni M, Dellapasqua S, Pruneri G, Mastropasqua MG, Luini A, Bassi F, Pagani G, Viale G and Goldhirsch A: Proposed new clinicopathological surrogate definitions of luminal A and luminal B (HER2-negative) intrinsic breast cancer subtypes. Breast Cancer Res 16: R65, 2014.

23 Guller U, Nitzsche EU, Shirp U, Viehl CT, Torhorst J, Moch H, Langer I, Marti WR, Oertli D, Harder F and Zuber M: Selective axillary surgery in breast cancer patients based on positron emission tomography with 18F-fluoro-2-deoxy-D-glucose: not yet. Breast Cancer Res Treat 71: 171-173, 2002.

24 Groheux D, Hindié E, Delord M, Giacchetti S, Hamy AS, de Bazelaire C, de Roquancourt A, Vercellino L, Toubert ME, Merlet $\mathrm{P}$ and Espié M: Prognostic impact of (18)FDG-PET-CT findings in clinical stage III and IIB breast cancer. J Natl Cancer Inst 104: 1879-1887, 2012.

25 Kim J, Lee J, Chang E, Kim S, Suh K, Sul J, Song I, Kim Y and Lee C: Selective sentinel node plus additional non-sentinel node biopsy based on an FDG-PET/CT scan in early breast cancer patients: single institutional experience. World J Surg 33(5): 943-949, 2009.

26 Liu Y: Role of FDG PET-CT in evaluation of locoregional nodal disease for initial staging of breast cancer. World J Clin Oncol 5(5): 982-989, 2014.

27 Hodgson NC and Gulebchyn KY: Is there a role for positron emission tomography in breast cancer staging? J Clin Oncol 26: 712-720, 2008.

28 Wahl RL, Siegel BA, Coleman RE, Gatsonis CG and PET Study Group: Prospective multicenter study of axillary nodal staging by positron emission tomography in breast cancer; a report of the staging breast cancer with PET Study Group. J Clin Oncol 22: 277-285, 2004.

29 Veronesi U, De Cicco C, Galimberti VE, Fernandez JR, Rotmensz N, Viale G, Spano G, Luini A, Intra M, Veronesi P, Berrettini A and Paganelli G: A comparative study on the value of FDG-PET and sentinel node biopsy to identify occult axillary metastases. Ann Oncol 18: 473-478, 2007.

30 Van der Hoeven JJ, Hoekstra OS, Comans EF, Pijpers R, Boom RP, van Geldere D, Meijer S, Lammertsma AA and Teule GJ: Determinants of diagnostic performance of [F-18] fluorodeoxyglucose positron emission tomography for axillary staging in breast cancer. Ann Surg 236: 619-624, 2002. 
31 Orsaria P, Varvaras D, Vanni G, Pagnani G, Scaggiante J, Frusone F, Granai AV, Petrella G and Buonomo OC: Nodal status assessment in breast cancer: strategies of clinical grounds and quality of life implications. Int J Breast Cancer 2014: 469803, 2014.

32 Greco M, Agresti R, Cascinelli N, Casalini P, Giovanazzi R, Maucione A, Tomasic G, Ferraris C, Ammatuna M, Pilotti S and Menard S: Breast cancer patients treated without axillary surgery: clinical implication and biologic analysis. Ann Surg 232: 1-7, 2000

33 Langer I, Marti WR, Guller U, Moch H, Harder F, Oertli D and Zuber M: Axillary recurrence rate in breast cancer patients with negative sentinel lymph node (SLN) or SLN micrometastases: prospective analysis of 150 patients after SLN biopsy. Ann Surg 241(1): 152-158, 2005.

34 Zhang X1, Wu F and Han P: The role of (18)F-FDG PET/CT in the diagnosis of breast cancer and lymph nodes metastases and micrometastases may be limited. Hell J Nucl Med 17(3): 177183,2014

35 Heusner TA1, Kuemmel S, Hahn S, Koeninger A, Otterbach F, Hamami ME, Kimmig KR, Forsting M, Bockisch A, Antoch G and Stahl A: Diagnostic value of full-dose FDG PET/CT for axillary lymph node staging in breast cancer patients. Eur J Nucl Med Mol Imaging 36(10): 1543-1550, 2009.

36 Menard S, Bufalino R, Rilke F, Cascinelli N, Veronesi U and Colnaghi MI: Prognosis based on primary breast carcinoma instead of pathological nodal status. Br J Cancer 70: 709-712, 1994.

37 An YS, Kang DK, Jung Y and Kim TH: Volume-based metabolic parameter of breast cancer on preoperative 18F-FDG PET/CT could predict axillary lymph node metastasis. Medicine (Baltimore) 96(45): e8557, 2017.

38 Groheux D, Giacchetti S, Moretti J-L, Porcher R, Espie' M, Lehmann-Che J, de Roquancourt A, Hamy AS, Cuvier C, Vercellino L and Hindié E: Correlation of high 18F-FDG uptake to clinical, pathological and biological prognostic factors in breast cancer. Eur J Nucl Med Mol Imaging 38: 426-435, 2011.

39 Gil-Rendo A, Martı́nez-Regueira F, Zornoza G, Garc1'a-Velloso MJ, Beorlegui C and Rodriguez-Spiteri N: Association between [18F]fluorodeoxyglucose uptake and prognostic parameters in breast cancer. Br J Surg 96: 166-170, 2009.

40 Mavi A, Cermik TF, Urhan M, Puskulcu H, Basu S, Yu JQ, Zhuang H, Czerniecki B and Alavi A: The effects of estrogen, progesterone, and C-erbB-2 receptor states on 18F-FDG uptake of primary breast cancer lesions. J Nucl Med 48: 1266-1272, 2007.

41 Osborne JR, Port E, Gonen M, Doane A, Yeung H, Gerald W, Cook JB and Larson S: 18F-FDG PET of locally invasive breast cancer and association of estrogen receptor status with standardized uptake value: microarray and immunohistochemical analysis. J Nucl Med 51: 543-550, 2010

42 Wo JY, Chen K, Neville BA, Lin NU and Punglia RS: Effect of very small tumor size on cancer-specific mortality in nodepositive breast cancer. J Clin Oncol 29: 2619-2627, 2011.

43 Avril N, Menzel M, Dose J, Schelling M, Weber W, Jaenicke F, Nathrath $\mathrm{W}$ and Schwaiger M: Glucose metabolism of breast cancer assessed by 18F-FDG PET: histologic and immunohistochemical tissue analysis. J Nucl Med 42: 9-16, 2001.

44 Oshida M, Uno K, Suzuki M, Nagashima T, Hashimoto H, Yagata $\mathrm{H}$, Shishikura T, Imazeki K and Nakajima N: Predicting the prognoses of breast carcinoma patients with positron emission tomography using 2-deoxy-2 fluoro[18F]-D-glucose. Cancer 82: 2227-2234, 1998

45 Higashi T, Tamaki N, Honda T, Torizuka T, Kimura T, Inokuma T, Ohshio G, Hosotani R, Imamura M and Konishi J: Expression of glucose transporters in human pancreatic tumors compared with increased FDG accumulation in PET study. J Nucl Med 38 : 1337-1344, 1997.

46 Heudel P, Cimarelli S, Montella A, Bouteille C and Mognetti T: Value of PET-FDG in primary breast cancer based on histopathological and immunohistochemical prognostic factors. Int J Clin Oncol 15: 588-593, 2010.

47 Liao CT, Chang JT, Wang HM, Ng SH, Huang SF, Chen IH, Hsueh C, Lee LY, Lin CH, Cheng AJ and Yen TC: Preoperative [18F]fluorodeoxyglucose positron emission tomography standardized uptake value of neck lymph nodes may aid in selecting patients with oral cavity squamous cell carcinoma for salvage therapy after relapse. Eur J Nucl Med Mol Imaging 36: 1783-1793, 2009.

48 Kidd EA, Siegel BA, Dehdashti F and Grigsby PW: Pelvic lymph node F-18 fluorodeoxyglucose uptake as a prognostic biomarker in newly diagnosed patients with locally advanced cervical cancer. Cancer 116: 1469-1475, 2010.

49 Song BI1, Lee SW, Jeong SY, Chae YS, Lee WK, Ahn BC and Lee J: 18F-FDG uptake by metastatic axillary lymph nodes on pretreatment PET/CT as a prognostic factor for recurrence in patients with invasive ductal breast cancer. J Nucl Med 53(9): 1337-1344, 2012.

50 Bustreo S, Osella-Abate S, Cassoni P, Donadio M, Airoldi M, Pedani F, Papotti M, Sapino A and Castellano I: Optimal Ki67 cut-off for luminal breast cancer prognostic evaluation: a large case series study with a long-term follow-up. Breast Cancer Res Treat 157: 363-371, 2016.

51 Luo J, Zhou Z, Yang Z, Chen X, Cheng J, Shao Z, Guo X, Tuan $\mathrm{J}, \mathrm{Fu} \mathrm{X}$ and $\mathrm{Yu} \mathrm{X}$ : The value of 18F-FDG PET/CT imaging combined with pretherapeutic ki67 for early prediction of pathologic response after neoadjuvant chemotherapy in locally advanced breast cancer. Medicine (Baltimore) 95: e2914, 2016.

52 Ozguven S, Inanir S, Turoglu HT, Erdil TY, Ugurlu MU and Gulluoglu B: 2-(fluorine-18)-fluoro-2-deoxy-D-glucose positron emission tomography/computed tomography after breast conserving surgery: correlation with molecular markers of breast cancer. Indian J Nucl Med 31: 166-171, 2016.

53 Paik S, Kim C and Wolmark N: HER2 status and benefit from adjuvant trastuzumab in breast cancer. N Engl J Med 358: 1409$1411,2008$.

54 Ueda S, Tsuda H, Asakawa H, Shigekawa T, Fukatsu K, Kondo N, Yamamoto M, Hama Y, Tamura K, Ishida J, Abe Y and Mochizuki $\mathrm{H}$ : Clinicopathological and prognostic relevance of uptake level using 18F-fluorodeoxyglucose positron emission tomography/ computed tomography fusion imaging (18F-FDG PET/CT) in primary breast cancer. Jpn J Clin Oncol 38: 250-258, 2008.

55 Sanli Y, Kuyumcu S, Ozkan ZG, Işik G, Karanlik H, Guzelbey B, Turkmen C, Ozel S, Yavuz E and Mudun A: Increased FDG uptake in breast cancer is associated with prognostic factors. Ann Nucl Med 26: 345-350, 2012.

56 Buck A, Schirrmeister H, Kühn T, Shen C, Kalker T, Kotzerke J, Dankerl A, Glatting G, Reske S and Mattfeldt T: FDG uptake in breast cancer: correlation with biological and clinical prognostic parameters. Eur J Nucl Med Mol Imaging 29: 1317$1323,2002$. 
57 Shimoda W, Hayashi M, Murakami K, Oyama T and Sunagawa M: The relationship between FDG uptake in PET scans and biological behavior in breast cancer. Breast Cancer 14: 260-268, 2007.

58 Mavi A, Cermik TF, Urhan M, Puskulcu H, Basu S, Yu JQ, Zhuang $\mathrm{H}$, Czerniecki B and Alavi A: The effects of estrogen, progesterone, and C-erbB-2 receptor states on 18F-FDG uptake of primary breast cancer lesions. J Nucl Med 48: 1266-1272, 2007.

59 Song BI, Lee SW, Jeong SY, Chae YS, Lee WK, Ahn BC and Lee J: 18F-FDG uptake by metastatic axillary lymph nodes on pretreatment $\mathrm{PET} / \mathrm{CT}$ as a prognostic factor for recurrence in patients with invasive ductal breast cancer. J Nucl Med 53(9): 1337-1344, 2012.

60 Futamura M, Asano T, Kobayashi K, Morimitsu K, Nawa M, Kanematsu M, Morikawa A, Mori R and Yoshida K: Prediction of macrometastasis in axillary lymph nodes of patients with invasive breast cancer and the utility of the SUV lymph node/tumor ratio using FDG-PET/CT. World J Surg Oncol 13: 49, 2015.

$61 \mathrm{Kim}$ BS and Sung SH: Usefulness of 18F-FDG uptake with clinicopathologic and immunohistochemical prognostic factors in breast cancer. Ann Nucl Med 26: 175-183, 2012.

62 Buonomo OC, Caredda E, Portarena I, Vanni G, Orlandi A, Bagni C, Petrella G, Palombi L and Orsaria P: New insights into the metastatic behavior after breast cancer surgery, according to well-established clinicopathological variables and molecular subtypes. PLoS One 12(9): e0184680, 2017.

63 Brenton JD, Carey LA, Ahmed AA and Caldas C: Molecular classification and molecular forecasting of breast cancer: ready for clinical application? J Clin Oncol 23: 7350-7360, 2005.

64 Vander Heiden MG, Plas DR, Rathmell JC, Fox CJ, Harris MH and Thompson CB: Growth factors can influence cell growth and survival through effects on glucose metabolism. Mol Cell Biol 21: 5899-5912, 2001.

65 Bertucci F, Finetti P and Birnbaum D: Basal breast cancer: a complex and deadly molecular subtype. Curr Molec Med 12: 96$110,2012$.

66 García Vicente AM, Soriano Castrejón Á, León Martín A, Chacón López- Muñiz I, Muñoz Madero V, Muñoz Sánchez Mdel M, Palomar Muñoz A, Espinosa Aunión R and González Ageitos A: Molecular subtypes of breast cancer: metabolic correlation with 18F-FDG PET/CT. Eur J Nucl Med Mol Imaging 40: 1304-1311, 2013.
67 Radan L, Ben-Haim S, Bar-Shalom R, Guralnik L and Israel O: The role of FDG-PET/CT in suspected recurrence of breast cancer. Cancer 107(11): 2545-2551, 2006.

68 Piva R, Ticconi F, Ceriani V, Scalorbi F, Fiz F, Capitanio S, Bauckneht M, Cittadini G, Sambuceti G and Morbelli S: Comparative diagnostic accuracy of 18F-FDG PET/CT for breast cancer recurrence. Breast Cancer (Dove Med Press) 9: 461-471, 2017.

69 Kaida H, Toh U, Hayakawa M, Hattori S, Fujii T, Kurata S, Kawahara A, Hirose $\mathrm{Y}$, Kage $\mathrm{M}$ and Ishibashi $\mathrm{M}$ : The relationship between $18 \mathrm{~F}-\mathrm{FDG}$ metabolic volumetric parameters and clinicopathological factors of breast cancer. Nucl Med Commun 34: 562-570, 2013.

70 Kajáry K, Tókés T, Dank M, Kulka J, Szakáll S Jr and Lengyel Z: Correlation of the value of 18F-FDG uptake, described by $\mathrm{SUV}_{\mathrm{max}}, \mathrm{SUV}_{\mathrm{avg}}$, metabolic tumour volume and total lesion glycolysis, to clinicopathological prognostic factors and biological subtypes in breast cancer. Nucl Med Commun 36: 28-37, 2015.

71 Hatt M, Cheze-Le Rest C, Aboagye EO, Kenny LM, Rosso L, Turkheimer FE, Albarghach NM, Metges JP, Pradier O and Visvikis D: Reproducibility of 18F-FDG and 3'-deoxy-3'-18Ffluorothymidine PET tumor volume measurements. J Nucl Med 51: 1368-1376, 2010.

72 Kruse V, Mees G, Maes A, D'Asseler Y, Borms M, Cocquyt V and Van De Wiele C: Reproducibility of FDG PET based metabolic tumor volume measurements and of their FDG distribution within. Q J Nucl Med Mol Imaging 59: 462-468, 2015.
Received October 20, 2018

Revised November 10, 2018 Accepted November 15, 2018 